\title{
Experimental and Finite Element (FE) Modelling of Timber Fencing for Benchmarking Novel Composite Fencing
}

\author{
Adeayo Sotayo*a ${ }^{\mathrm{a}}$, Sarah Green ${ }^{\mathrm{a}}$ and Geoffrey Turvey ${ }^{\mathrm{a}}$

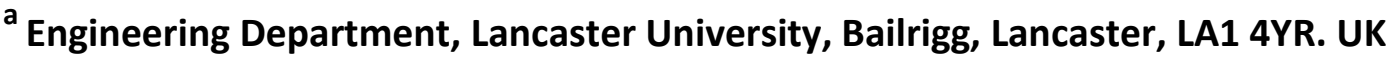

\begin{abstract}
Timber is a widely used composite material in structural applications. However, with global forest loss occurring at a high rate and deforestation accounting for about $12 \%$ of global $\mathrm{CO}_{2}$ emissions, there is an increasing demand for alternative structural materials with a lower carbon footprint to mitigate climate change. This has led to an increased interest in the development of novel structural composites. This paper describes an investigation of the load-deformation behaviour of a typical post and rail fence fabricated from timber sections.
\end{abstract}

Prior to testing the fence, bending tests were carried out on the timber posts and rails to determine their elastic flexural moduli. Tip-loaded cantilever bending tests were also carried out to determine the semi-rigid rotational stiffness of the bolted joint at the base of the posts. Finite Element (FE) analyses were then carried out using ANSYS software to investigate the structural behaviour of the timber fence. The FE results were compared with the experimental results and shown to be in good agreement. As there are no structural load-bearing standards for agricultural fencing, the experimental and FE timber fencing results provide useful benchmarks for assessing the structural stiffness of novel recycled composite materials and components.

KEYWORDS: TIMBER FENCING; FINITE ELEMENT ANALYSIS; STRUCTURAL COMPOSITES; BOLTED JOINTS

*Corresponding author. Email address: a.sotayo@lancs.ac.uk (Adeayo Sotayo) 


\section{Introduction}

Timber is a natural composite material commonly used in structural load-bearing applications such as fencing, furniture, flooring, framing, panelling, scaffolding and many other building components, because of its good mechanical properties. However, the mechanical properties of timber vary widely due to its natural origin [1]. These variations are, in part, as a result of the growth conditions of timber which are influenced by various environmental factors such as soil type, water supply and nutrients [1]. There are other factors that affect the mechanical properties of timber; these include temperature, density, moisture content and humidity [2]. Timber is also an anisotropic material, it has three principal axes: longitudinal, radial and tangential axes (see Figure 1). The longitudinal axis is parallel to the fibre direction, the radial axis is perpendicular to the fibre direction and normal to the growth rings, and the tangential axis is perpendicular to the fibre direction and tangential to the growth rings. However, according to Isopescu et al. [3], though the mechanical properties of timber are direction dependent, the difference between the mechanical properties in the radial and tangential directions is small compared to the difference between the longitudinal and the radial/tangential directions.

In general structural design, the mechanical properties of timber are classified into two groups; properties parallel-to-the-grain (longitudinal) and perpendicular-to-the-grain (tangential and radial). The classification system according to BS EN 338 [4] shows that the elastic moduli of timber parallel-to-the-grain and perpendicular-to-the-grain range from 7 $20 \mathrm{GPa}$ and $0.23-1.33 \mathrm{GPa}$ respectively. These values show that timber is significantly stiffer parallel-to-the-grain compared to perpendicular-to-the-grain. Hence, in structural load-bearing applications, timber is typically loaded parallel-to-the-grain.

Although timber is a widely used structural material, global forest loss is occurring at a rate of 13.7 million hectares $\left(137,000 \mathrm{~km}^{2}\right)$ per year with the timber trade being a major cause of this loss [5]. Furthermore, deforestation is responsible for the release of stored carbon, and accounts for about $12 \%$ of global $\mathrm{CO}_{2}$ emissions [6]. This has led to an increased demand for alternative structural materials with lower carbon footprints, as reduction in deforestation is significant in efforts to mitigate global climate change. 
Timber and PVC are common materials used in agricultural fencing, but timber predominates $[7,8]$. Figure 2 shows a typical timber post and rail agricultural fencing system. The bases of the posts (approximately $600-750 \mathrm{~mm}$ in length) are typically concreted in the ground to give a rigid base support [9].The rails are commonly attached to the posts with nails, which typically vary from $2.65-8 \mathrm{~mm}$ in diameter [10].

The motivation for this study is the current lack of structural load-bearing standards for agricultural timber fencing. This study also provides improved scientific knowledge of timber fencing, which may be transformed into useful structural design guidance. Hence, this study describes an investigation and quantification of the structural load-deformation behaviour of a typical agricultural timber post and rail fence - the target application for replacement with alternative novel and lower carbon footprint composite materials/components.

Load tests were carried out on a two-bay post and rail fence, which is representative of typical multi-bay fencing systems. It was decided to test a two-bay rather than a one-bay frame because the former is more representative of the practical scenario compared to the latter. Turvey [11] also explained that load tests on multi-bay frames provide information about the stiffness benefits which may occur as a result of the structural continuity across bays. Details of the joint used to secure the bases of the posts to their foundations are described. As there was neither data nor information on the mechanical properties of the timber sections, three-point bending tests were carried out on the posts and rails to determine their elastic flexural moduli and these tests are described. Thereafter, details of tip-loaded cantilever bending tests carried out to determine the rotational stiffness of the joint at the base of the posts are presented. Furthermore, quantifying the stiffness of an end connection is useful in structural design, as there is always some rotational stiffness present in practical connections [12]. The experimental setup, overall geometry and loading procedure adopted for the load tests on the two-bay timber fence are described.

Finite Element (FE) modelling of the fencing system was carried out using ANSYS [13] to determine how accurately the actual load-deformation response can be simulated. Detailed descriptions of two FE analyses carried out are presented; the first being a cantilever semirigid beam analysis, and the other being the two-bay timber fence analysis. The results of 
the FE cantilever semi-rigid beam analysis were compared with those of the experimental tip-loaded cantilever bending tests, and used to validate the FE analysis technique. The technique shows that the rotational stiffness of the joint at the base of the posts can be used to develop an accurate FE model of the fencing system. Thereafter, FE analyses were carried out to investigate the load-deformation response of the two-bay timber fence, and compared with the experimental test results. The FE models can then be used to investigate the load-deformation response of fence assemblies, whilst varying their overall geometry, and the mechanical and geometric properties of the joints and structural members (posts and rails). The study is concluded with a summary of key experimental and FE analyses, which provide useful benchmarks for assessing the structural stiffness of novel fencing materials and structures.

\section{Experimental Test Setup}

Load tests were carried out on a two-bay post and rail fence that comprised of three posts and two rails, as shown in Figure 3. The rails were connected to the posts with two nails (see Figure 4). The nails had a shank diameter of $4 \mathrm{~mm}$ and a length of $100 \mathrm{~mm}$. The rail-to-post nailed connection configuration was based on the guidance given in TRADA [14], and thus the distance between each nail and edge of the timber rail was at least $30 \mathrm{~mm}$ (see Figure 4). The rail-to-post nailed connection configuration is also similar to that used in practice. The two-bay timber frame had a total of six rail-to-post nailed connections.

It is worth highlighting that the bases of timber posts are typically concreted into the ground in practice and their stiffnesses may vary and depend on several environmental factors (i.e. moisture content, temperature). However, for this study, the posts were rigidly clamped in the laboratory with a thick steel plate, nuts and threaded steel rods fastened to a welded steel angle. Figure 5 shows the layout details of the bolted joint at the base of the posts.

A $15 \mathrm{~mm}$ thick steel plate was bolted on the front face of the timber post to a welded steel angle with triangular gusset plates on the back face. Eight nuts and four $150 \mathrm{~mm}$ long by 12 $\mathrm{mm}$ diameter threaded steel rods were used to bolt the steel plate to the steel angle. The four bolt holes in the steel plate, welded steel angle and timber post were also $12 \mathrm{~mm}$ in diameter. The nuts were torqued to $30 \mathrm{Nm}$. The horizontal leg of the welded steel angle was bolted to a rigid steel reaction frame. 


\subsection{Material Description}

The timber post and rail sections were supplied by Equestrian Surfaces and are typical of those used for agricultural fencing. The timber sections were ungraded and are believed to be the softwood species spruce. The moisture content of the posts and rails was measured with ST-125 model moisture meter, and the average moisture content was $12( \pm 2) \%$. The timber posts and rails were weighed, and their mass densities are listed in Table 1 . The densities were measured to characterise the physical properties of the timber sections. The average density of the timber posts and rails was $498 \mathrm{~kg} / \mathrm{m}^{3}$, and falls within the range of average densities $\left(350-550 \mathrm{~kg} / \mathrm{m}^{3}\right.$ ) for softwood species given in BS EN 338 [4]. It is also worth noting that the classification system for structural timber given in BS EN 338 [4] is based on samples with approximately $12 \%$ moisture content.

\subsection{Three-Point Bending Tests on Timber Posts and Rails}

The flexural modulus is part of the information required to determine the flexural stiffness of the timber post and rail sections. It is also an important material property that is required to model the load-deformation behaviour of timber fencing in ANSYS. Figure 6a shows a sketch of the three-point beam bending test setup. Figure $6 \mathrm{~b}$ shows a sketch of the crosssection of the beam. The timber sections were simply supported on steel rollers and loaded by means of dead weights added to a hanger located at mid-span. The centre deflection corresponding to each increment of load was recorded by a dial gauge with a $50 \mathrm{~mm}$ travel and a displacement resolution of $0.01 \mathrm{~mm}$. The average dimensions of the posts and rails are listed in Table 2. Three posts and two rails were tested three times in bending and average deflections were used to plot their load-deflection responses.

Equation (1) gives the centre deflection, $\mathbf{w}_{c}$ of a simply supported beam subjected to threepoint bending when shear deformation is neglected.

$$
\begin{gathered}
\mathrm{w}_{\mathrm{c}}=\frac{\mathrm{FL}^{3}}{48 \mathrm{EI}} \\
\mathrm{E}=\frac{\mathrm{mL}^{3}}{48 \mathrm{I}}
\end{gathered}
$$


where $\mathrm{m}=\mathrm{F} / \mathrm{w}_{\mathrm{c}}$

In Equations (1) and (2), F is the centrally applied load, L is the test span, E is the flexural modulus, $\mathrm{I}$ is the second moment of area with respect to the $\mathrm{x}$-axis (see Figure $6 \mathrm{~b}$ ) and $\mathrm{m}$ is the slope of the load-deflection curve.

\subsection{Cantilever Test on a Timber Post}

Tip-loaded cantilever bending tests were carried out to determine the rotational stiffness of the bolted joint used to secure the base of the timber post to the foundation. The behaviour of a semi-rigid joint is characterised by its moment-rotation curve. Obtaining the rotational stiffnesses of the bolted base joints also allows the development of a more accurate FE model (rather than assuming rigidly fixed base joints) for the two-bay timber fence. This is because there is always a quantifiable amount of rotational stiffness present in joints. This value can then be used as the end connection stiffness in the FE analysis for the two-bay timber fence.

A sketch of the semi-rigid beam analysis model is shown in Figure 7. The beam, $A B$ is assumed to be uniform, straight and of span, L. Point $A$ is the semi-rigid bolted joint. Equation (3) gives the deflection at point $B$, when shear deformation is neglected. Equation (4) gives the moment-rotation relationship of the joint at Point A.

$$
\begin{gathered}
\mathrm{w}_{\mathrm{B}}=\frac{\mathrm{FL}^{3}}{3 \mathrm{EI}}+\frac{\mathrm{FL}^{2}}{\mathrm{~K}} \\
\mathrm{M}_{\mathrm{A}}=\mathrm{K} \emptyset_{\mathrm{A}} \\
\mathrm{FL}=\mathrm{K}\left(\frac{\mathrm{w}_{\mathrm{B}}}{\mathrm{L}}-\frac{\mathrm{FL}^{2}}{3 \mathrm{EI}}\right)
\end{gathered}
$$

In Equations (3) - (5), $W_{b}$ is the deflection at point $B, F$ is the load applied at point $B, L$ is the cantilever span, $\mathrm{E}$ is the elastic flexural modulus (obtained from the three-point bending tests), $\mathrm{I}$ is the second moment of area with respect to the plane of flexure, $M_{A}$ is the moment at the semi-rigid support (bolted joint), $\emptyset_{A}$ is the rotation at $A$, and $K$ is the rotational stiffness of the bolted joint. The length, $L$ of the cantilever beam was taken as the 
distance from the loading point to the top of the bolted steel plate. Re-arranging Equation (3) gives Equation (5). Equation (4) can be compared to Equation (5), in which, the FL term represents the moment at the semi-rigid support, $\mathrm{M}_{\mathrm{A}}$ and the $\left(\frac{\mathrm{w}_{\mathrm{B}}}{\mathrm{L}}-\frac{\mathrm{FL}^{2}}{3 \mathrm{EI}}\right)$ term represents the semi-rigid joint rotation at A, namely $\emptyset_{A}$. Thus, a plot of FL against $\left(\frac{\mathrm{w}_{\mathrm{B}}}{\mathrm{L}}-\frac{\mathrm{FL}^{2}}{3 \mathrm{EI}}\right)$ yields a straight line with a gradient of $\mathrm{K}$, which is the rotational stiffness at joint $A$.

The cantilever test was carried out using the test rig shown in Figure 8, in which load was applied in increments of $98.1 \mathrm{~N}$ up to $784.8 \mathrm{~N}$. The loading point was located $40 \mathrm{~mm}$ below the top of the post. A dial gauge, which had a $50 \mathrm{~mm}$ travel and a displacement resolution of $0.01 \mathrm{~mm}$, was mounted at the back of the post to record the horizontal deflections corresponding to each load increment. Three repeat tests were carried out, and the average values were used to determine the rotational stiffness of the bolted joint at the base of the post.

\subsection{Load-deflection Test on the Two-Bay Timber Fence}

A schematic drawing showing the loading arrangement and overall geometry of the two-bay timber fence is shown in Figure 9. The two-bay timber fence was tested under incremental static loading applied at the mid-point on the top rail (at Node B in Figure 9). Loading was applied normal to the plane of the timber frame. A $100 \mathrm{~N}$ load was applied initially and then increased in $100 \mathrm{~N}$ increments. The fence was tested to a maximum load of $1400 \mathrm{~N}$ to ensure that its deformation was elastic.

The deflections corresponding to each load increment at the tops of the three posts (at Nodes A - C in Figure 9) were measured with dial gauges. The test procedure was repeated three times. Figure 10 shows the two-bay timber frame and the loading arrangement. A steel disk, with a ball joint (see Figure 11) was bonded to the face of the top rail (Rail 1) at its connection to the centre post (Post 2), where load was applied by means of a manually operated hydraulic jack with its base bolted to a steel reaction frame. The hydraulic jack was fitted with a $10 \mathrm{kN}$ capacity load cell, which was connected to a load readout. The steel reaction frame was bolted to the laboratory floor. 


\section{Experimental Test Results}

\subsection{Results and Discussion of Three-Point Bending Tests on the Posts and Rails}

The average deflection values for the posts and rails were used to plot their load-centre deflection responses, which are shown in Figures 12 and 13. The load-centre deflection responses are linear, and regression lines were fitted to the data in order to determine their slopes (or transverse stiffnesses), $m$. These slopes were used to determine the flexural modulus for each timber section using Equation (2).

Table 3 lists the transverse stiffnesses and flexural moduli of the timber posts and rails. The results show that the average flexural moduli of the posts and rails vary from 8.1 GPa to 13.5 GPa. The average flexural modulus for the five timber sections was $10.0 \mathrm{GPa}$ and their standard deviation and coefficient of variation were $5.0 \mathrm{GPa}$ and $45 \%$ respectively. The large differences between the measured flexural moduli of the timber posts and rails illustrate the natural variability of timber and are also typical of ungraded timber sections.

\subsection{Results and Discussion of Tip-loaded Cantilever Bending Test}

The average deflection values were used to calculate the rotational stiffness of the bolted joint at the base of the post. Using Equations (4) and (5), a moment-rotation plot for the timber post is shown in Figure 14. A regression line was fitted to the plot to determine the rotational stiffness, $\mathrm{K}$ of the bolted joint at the base of the post to be $3 \times 10^{5} \mathrm{Nm} / \mathrm{rad}$.

\subsection{Results and Discussion of the Load-deflection Test on Two-bay Timber Frame}

The results for the three repeat load tests on the two-bay timber frame showed good repeatability. Figure 15 shows a plot of the load versus average deflection responses at Nodes A - C of the two-bay timber frame. The load-deflection plots for the three Nodes A$\mathrm{C}$ show linear responses. The timber frame supported a maximum load of $1400 \mathrm{~N}$ without showing any signs of damage. The average transverse deflections at a maximum load of $1400 \mathrm{~N}$ at Nodes A - C are given in Table 4. As expected, Node B (being the loading point), had the largest deflection of $27.6 \mathrm{~mm}$ for an applied maximum load of $1400 \mathrm{~N}$. Nodes $\mathrm{A}$ and 
C had significantly lower average transverse deflections of $3.7 \mathrm{~mm}$ and $3.3 \mathrm{~mm}$ respectively, reflecting the limited load distribution effects produced by the rails. The difference in the average deflections at Nodes $\mathrm{A}$ and $\mathrm{C}$ is small, and can also be attributed to the differences in the flexural moduli of the timber sections.

As the rails do not fully transmit the load applied on the centre post (Node B) to the two outer posts (Nodes $A$ and $C$ ), the transverse stiffness of the two-bay timber frame was determined by dividing the maximum load of $1400 \mathrm{~N}$ by the average transverse deflection at Node B. Therefore, the transverse stiffness for the two-bay fence was $50.7 \mathrm{~N} / \mathrm{mm}$.

\section{Finite Element (FE) Model and Analysis}

FE analyses were carried out using ANYSY [13], to simulate the structural behaviour of the two-bay timber frame. Two different FE analyses were carried out; a cantilever semi-rigid beam analysis was carried out to validate the FE analysis technique, and the results were compared with the experimental tip-loaded cantilever bending test results. The other FE analysis was the two-bay timber frame analysis, and was compared with the results of the experimental load tests.

Line bodies utilising BEAM188 elements were used to represent the posts and rails for computational efficiency. MPC184 elements (Multi-Point Constraint) were used to represent the bolted base joints. The BEAM188 element utilises a cubic interpolation function, hence increasing the number of elements per post/rail does not significantly affect the deformation results. The BEAM188 and MPC184 elements both have six degrees of freedom per node. The six degrees of freedom include: three translational $\left(U_{X}, U_{Y}, U_{Z}\right)$ and three rotational (ROTX, ROTY and ROTZ) displacements (see Figure 16). It is worth noting that an MPC184 element is defined by two coincident nodes used for modelling joints in ANSYS. Hence, different types of joints can be represented by imposing the appropriate kinematic constraints on the degrees of freedom. The translational and rotational stiffnesses can be specified as coefficients of a $6 \times 6$ stiffness matrix.

For this study, as the two-bay timber posts and rails mainly resist bending; only the parallelto-the-grain timber properties significantly affect the FE simulation results. Therefore, a simplified isotropic linear-elastic material model was used in the FE analyses. 


\subsection{Cantilever Beam FE Model and Analysis}

In the FE cantilever beam analysis, a semi-rigid joint was created at Point A (see Figure 17), by fixing the three translational $\left(U_{X}, U_{Y}, U_{Z}\right)$ and two rotational degrees of freedom (ROTX and ROTY), leaving only one degree of freedom (rotation about the z-axis, ROTZ) illustrated in Figure 18.

A rotational stiffness of $3 \times 10^{5} \mathrm{Nm} / \mathrm{rad}$, which was obtained from the experimental tiploaded cantilever test, was used to represent the rotational stiffness about the z-axis at Point A. Load was applied at Point B in the negative Y-direction as illustrated in Figure 17. It should be appreciated that the coordinate system at Point $B$ is the same as that at Point A. The flexural modulus of the post used for the cantilever test was $8.1 \mathrm{GPa}$. A Poisson's ratio for timber of 0.3 was used in the model.

\subsection{Two-Bay Timber Frame FE Model and Analysis}

Figure 19 shows the overall geometry, node and member labels of the two-bay timber frame model. All the nodes have the same coordinate system as highlighted at Node $E$ in Figure 19. Loading was applied at Node B in the negative Z-direction. Two different FE models were created to simulate load-deformation responses of the two-bay timber frame, and the displacements from each model were evaluated and compared with the experimental displacements. Table 5 gives details of the two types of joints used at the base of the posts in the FE models (Model 1 and Model 2) of the timber frame. The corresponding flexural moduli for each post and rail (from Table 3), obtained from threepoint bending tests were used in the FE models.

\section{Analysis and Discussion of the FE and Experimental Test Results}

Figure 20 shows a comparison between the experimental and FE analysis load versus deflection plots of a tip-loaded cantilever beam.

The results show that the FE model deflections are greater than those obtained from the experimental test for all loads. The deflections predicted by the FE Model lie in the range 2.1 
$-8.3 \%$ above the experimental test results. Table 6 shows the results of the FE Models 1 and 2 of the two-bay timber frame compared with the experimental deflections for a load of $1400 \mathrm{~N}$ applied at the top of Post 2. The ratios between the FE Model 1 and experimental test results for Nodes $A, B$ and $C$ are $0.76,0.82$ and 0.78 respectively. On the other hand, the ratios between the FE Model 2 and experimental results for Nodes A, B and C are 1.11, 0.97 and 1.18 respectively. This analysis shows that the results predicted by FE Model 2 show better agreement with the experimental deflections for Nodes A - C. This is because Model 1 assumed perfectly rigid supports at the base joints (Nodes D - F), which simplified the FE model. However, this resulted in a greater discrepancy between the Model 1 and experimental deflections. Model 2, on the other hand, utilised the rotational stiffness of the base joints obtained from the tip-loaded cantilever tests.

Figure 21 shows a contour plot (based on Model 2) of the transverse deflection of the twobay timber frame for the maximum applied load of $1400 \mathrm{~N}$. Compared with the experimental deflection at Node A, the deflections from FE Models 1 and 2 are $24 \%$ lower and $11 \%$ higher respectively. Furthermore, in comparison with the experimental deflections, the FE Model 1 and 2 deflections at Node C are $22 \%$ lower and $18 \%$ higher respectively. The Node B deflections obtained from FE models 1 and 2 are lower than the experimental deflections by $18 \%$ and $3 \%$ respectively. These analyses show that the deflections derived from FE Models 1 and 2 for Node B show a better agreement with the experimental values compared to Nodes $A$ and $C$. The relatively poorer agreement between the deflections at the outer posts (Nodes $A$ and C) compared to that of the centre post (Node B) may be due to the fact that the FE models assumed perfectly rigid rail-to-post joints, thus allowing a greater load distribution from the centre post to the outer posts. However, in reality, the rail-to-post nailed joints are not perfectly rigid. Figure 22 shows the comparison between the FE model 2 and experimental results at Nodes $A-C$, and the loaddeflection responses reflect a strong correlation between both sets of results.

Due to the variable nature of timber, a sensitivity analysis was carried out to investigate the effect of using the lowest and highest flexural moduli obtained from the three-point bending tests on the timber posts and rails. These lowest and highest flexural moduli were used as the elastic moduli in FE Model 2 for each of the posts and rails of the two-bay timber frame. The deflections at Nodes $A$ and $C$ were equal. The deflections obtained from 
using the lowest flexural modulus $(8.1 \mathrm{GPa}$ ) was $4 \mathrm{~mm}$ at Nodes $\mathrm{A}$ and $\mathrm{C}$, whereas, using the highest flexural modulus of $13.5 \mathrm{GPa}$ gave a $2.9 \mathrm{~mm}$ deflection (see Table 7).

Using the lowest and highest flexural moduli in FE Model 2, transverse deflections at Node B of $28.5 \mathrm{~mm}$ and $18.9 \mathrm{~mm}$ respectively were obtained. These transverse deflections also correspond to transverse stiffnesses of $49.1 \mathrm{~N} / \mathrm{mm}$ and $74.1 \mathrm{~N} / \mathrm{mm}$ (based on an applied load of $1400 \mathrm{~N}$ ), which represent lower and upper bound transverse stiffnesses.

\section{Conclusions}

The study describes an investigation of the load-deformation behaviour of a typical agricultural post and rail structure (fence) fabricated from timber sections - the target application for replacement with alternative novel and lower carbon footprint composite materials/components. The experimental tests carried out are described, and the test results have been analysed and discussed. Images of the test setups have also been presented. Finite Element analyses of the post and rail fence have been carried out, and compared with the experimental test results. Good correlation between the FE model analyses and experimental test results has been demonstrated.

A two-bay timber frame comprised of three posts and two rails was setup and tested. Steel nails were used to connect the rails to the posts. Threaded steel rods, nuts and a thick steel plate were used to fasten the base of the posts to a welded steel angle with triangular gusset plates. Tip-loaded cantilever bending tests were carried out on a post to determine the rotational stiffness of the bolted joint. The results of the cantilever tests show that the rotational stiffness of the bolted base joint was $3 \times 10^{5} \mathrm{Nm} / \mathrm{rad}$. The posts and rails were also tested in three-point bending to determine their elastic flexural moduli. The results of the three-point bending tests show that the average flexural modulus of the posts and rails varies from 8.1 - 13.5 GPa, not untypical of ungraded timber. The average flexural modulus for the five timber sections tested in three-point bending was $10 \mathrm{GPa}$. The standard deviation and coefficient of variation of the five timber sections were $5 \mathrm{GPa}$ and $45 \%$ respectively. The two-bay timber frame was tested under incremental static loading applied at the mid-point on the top rail. The transverse stiffness of the two-bay timber frame was 
calculated based on the deflection at the maximum load applied. The results show an average transverse stiffness of $50.7 \mathrm{~N} / \mathrm{mm}$.

Using the geometric properties, moduli and stiffnesses, FE analyses were carried out under loading to simulate the structural behaviour of the two-bay timber post and rail structure. A limitation with the FE analyses was the assumption of perfectly rigid rail-to-post joints, regardless of the fact that rail-to-post nailed joints have rotational stiffnesses. In addition, although timber is an anisotropic and inhomogeneous structural material, simplified isotropic linear-elastic FE models were created to simulate the structural behaviour of a two-bay timber fence.

Two FE models ( 1 and 2) were analysed. FE Model 1 used rigidly fixed joints at the base of the posts, whereas, FE Model 2 used semi-rigid base joints with a joint rotational stiffness of $3 \times 10^{5} \mathrm{Nm} / \mathrm{rad}$. The deflections predicted by FE Model 1 vary from about $18-24 \%$ lower than those from the experimental tests, whereas, the deflections predicted by FE Model 2 vary from about $3 \%$ lower to $18 \%$ higher than the experimental deflections. The study shows that modelling a semi-rigid joint with a specified rotational stiffness (rather than rigidly fixed joints), improved the FE model of the cantilever beam and two-bay timber frame. This also reflects the importance of quantifying the stiffnesses of connections in structural design. A sensitivity analysis was also carried out to investigate the effect of varying the flexural modulus of the post and rail sections of the two-bay timber frame. The findings from the analysis show that using flexural moduli of $8.1 \mathrm{GPa}$ and $13.5 \mathrm{GPa}$ resulted in transverse stiffnesses of $49.1 \mathrm{~N} / \mathrm{mm}$ and $74.1 \mathrm{~N} / \mathrm{mm}$ respectively, which represent lower and upper bound transverse stiffnesses of the two-bay timber fence.

In summary, as there are no current structural load-bearing standards for agricultural fencing, the experimental and FE timber fencing results provide useful benchmarks for assessing the structural stiffness of recycled composite materials and components for current and on-going research at Lancaster University's Engineering Department. 


\section{Acknowledgments}

The authors would like to acknowledge the financial support of the Centre for Global EcoInnovation and Lancaster University. The Centre for Global Eco-Innovation is part-financed by the European Regional Development Fund (Grant no. X02646PR). Furthermore, the authors also wish to thank Mr Mark Salisbury for his invaluable support and guidance with the experimental test work on the timber post and rail structure.

\section{References}

[1] D. Kretschmann, "Mechanical Properties of Wood," in Wood Handbook - Wood as an Engineering Material, R. Ross, Ed., ed Madison, WI: U.S. Department of Agriculture Forest Service, Forest Products Laboratory, 2010.

[2] S. V. Glass and S. L. Zelinka, "Moisture Relations and Physical Properties of Wood," in Wood Handbook - Wood as an Engineering Material, R. Ross, Ed., ed Madison, WI: U.S. Department of Agriculture Forest Service, Forest Products Laboratory, 2010.

[3] D. Isopescu, O. Stanila, I. Astanei, and C. Corduban, "Experimental Analysis of Wood Mechanical Properties from Bending, Tensile and Compression Tests," Romanian Journal of Materials, vol. 42, pp. 204-219, 2012.

[4] BS EN 338, "Structural timber. Strength classes," ed. London: British Standards Institution, 2009.

[5] M. Smith "Use of Recycled and Reclaimed Timbers," in Reuse of Materials and Byproducts in Construction A. Richardson, Ed., ed London: Springer, 2013, pp. 111-149.

[6] G. R. Van der Werf, D. C. Morton, R. S. DeFries, J. G. Olivier, P. S. Kasibhatla, R. B. Jackson, et al., "CO2 emissions from forest loss," Nature Geoscience, vol. 2, pp. 737-738, 2009.

[7] A. Teasdale, "Fencing construction " US Patent US5480126 A, 1996.

[8] Freedonia, "Fencing: United States," The Freedonia Group, Inc, Ohio2012.

[9] Timber fencing, Timber Research And Development Association, 1993.

[10] J. Porteous and A. Kermani, Structural timber design to Eurocode 5. Oxford: Blackwell, 2007.

[11] G. Turvey, "Experimental investigation of the load-deformation behaviour of pultruded GFRP modular and custom safety barriers," Composite Structures, vol. 133, pp. 659-666, 2015.

[12] G. J. Turvey, "Flexure of pultruded GRP beams with semi-rigid end connections," Composite Structures, vol. 47, pp. 571-580, 1999.

[13] ANSYS Workbench Release 15, "User's Guide ANSYS Inc.," ed.

[14] Design of structural timber connections, Timber Research and Development Association, 2003. 


\section{Figure Captions}

Figure 1: Three principal of axes of timber with respect to fibre direction and growth rings

Figure 2: Image of a typical timber post and rail agricultural fence

Figure 3: Illustrative diagram of the test setup for the timber post and rail fence

Figure 4: Details of the rail-to-post nailed connection

Figure 5: Details of the joint assembly at the base of the posts: (a) side view (b) front view

Figure 6: Sketch of the three-point beam bending test setup: (a) Side view and (b) Crosssection view

Figure 7: Semi-rigid beam analysis model

Figure 8: Image of cantilever test setup on timber post

Figure 9: Overall geometry of the timber post and rail fence

Figure 10: Load-deflection test on the two-bay timber frame

Figure 11: Close-up view of the loading arrangement on the two-bay timber frame

Figure 12: Load versus centre deflection plots for three posts (span $=1400 \mathrm{~mm}$ )

Figure 13: Load versus centre deflection plots for two rails (span $=2800 \mathrm{~mm}$ )

Figure 14: A plot of $M \_A$ against $\varnothing \_A$ for the tip-loaded cantilever beam

Figure 15: Load-deflection responses at Nodes A - C of the two-bay timber frame

Figure 16: A sketch showing the six degrees of freedom at a node

Figure 17: FE cantilever semi-rigid beam analysis model showing the coordinate system: (a) Side view (b) Normal view from Point A to B

Figure 18: Boundary conditions at Point A of the FE cantilever semi-rigid analysis model

Figure 19: Overall geometry of the two-bay FE frame model: (a) Front view (b) Edge view from Post 2 to 3

Figure 20: Comparison of FE and experimentally derived load versus deflection plots of a tiploaded cantilever beam

Figure 21: Contour plot showing the transverse deflection of the two-bay timber frame for a load of $1400 \mathrm{~N}$ at the top of Post 2

Figure 22: Comparison of FE and experimental load-deflection results for Nodes A - C 


\section{Table Captions}

Table 1: Mass, volume and density measurements of the timber posts and rails

Table 2: Average dimensions of the timber post and rails tested in three-point bending

Table 3: Transverse stiffnesses and flexural moduli of timber posts and rails

Table 4: Traverse deflections at Nodes A - C at the maximum load of $1400 \mathrm{~N}$

Table 5: Joint details used at the base of the posts in FE Model 1 and 2 of the two-bay timber frame

Table 6: Comparison of two-bay timber frame FE Models 1 and 2 with the experimental results for a maximum load of $1400 \mathrm{~N}$ applied at the top of Post 2

Table 7: Comparison between using the lowest and highest flexural moduli in FE Model 2 with the experimental test results for an applied load of $1400 \mathrm{~N}$ 